Supporting Information

\title{
Manipulating Uniform Nucleation to Achieve Dendrite-Free Zn Anode for Aqueous Zn-Ion Batteries
}

Penghui Cao, ${ }^{a}$ Jingjing Tang, ${ }^{a}$ Anran Wei, ${ }^{b}$ Qixian Bai, ${ }^{a}$ Qi Meng, ${ }^{a}$ Sicheng Fan, ${ }^{a}$ Han Ye, ${ }^{c}$ Yulin Zhou, ${ }^{d}$ Xiangyang Zhou, ${ }^{a, *}$ and Juan Yang, *

${ }^{a}$ School of Metallurgy and Environment, Central South University, Changsha, 410083, China.

${ }^{b}$ Department of Engineering Mechanics, School of Naval Architecture, Ocean and Civil Engineering, Shanghai Jiao Tong University, Shanghai 200240, China.

c State Key Laboratory of Information Photonics and Optical Communications, Beijing University of Posts and Telecommunications, Beijing 100876, China.

${ }^{d}$ Zhuzhou Smelter Group Co., Ltd., Zhuzhou, Hunan 412000, China.

*Corresponding Authors.E-mail address: hncsyjy308@163.com, j-yang@csu.edu.cn 

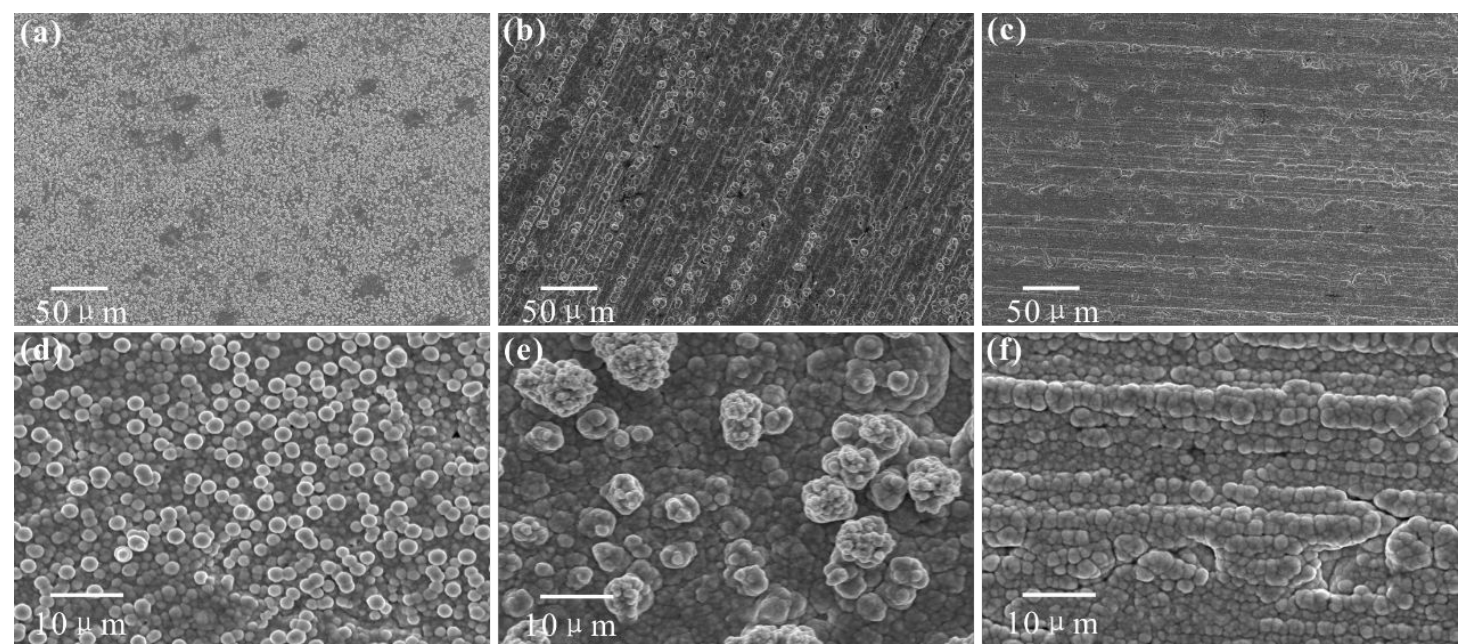

Figure S1. The SEM images of the surface of the $\mathrm{Zn}-\mathrm{ZnNi}$ prepared at a current density of $20 \mathrm{~mA}$ $\mathrm{cm}^{-2}$ for (a) $10 \mathrm{~min}$, (b) $30 \mathrm{~min}$, and (c) $20 \mathrm{~min}$. where the images of (d), (e), and (f) are the enlargement of the (a), (b), and (c), respectively.
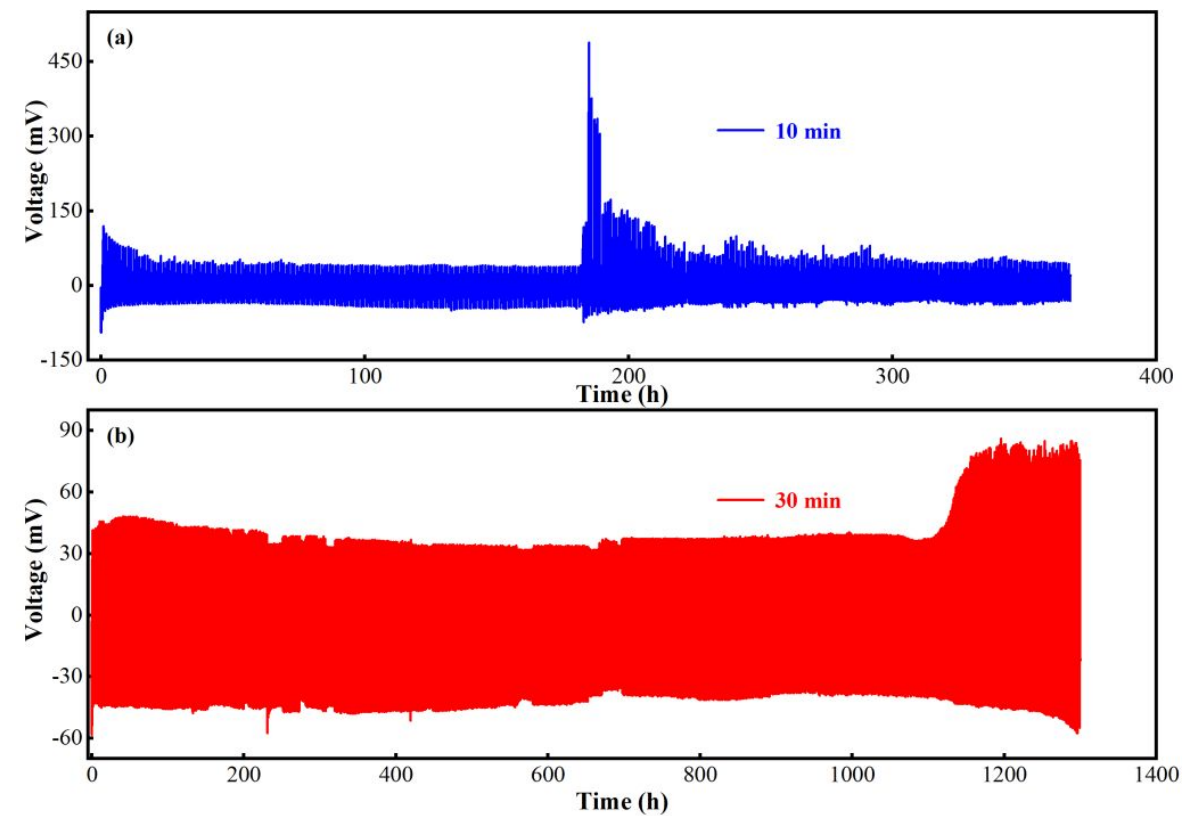

Figure S2. The cycling performance at $2 \mathrm{~mA} \mathrm{~cm}-2 / 1 \mathrm{mAh} \mathrm{cm}^{-2}$ of the symmetric cell with $\mathrm{Zn} @ \mathrm{ZnNi}$ anode prepared by the $20 \mathrm{~mA} \mathrm{~cm}{ }^{-2}$ for (a) $10 \mathrm{~min}$ and (b) $30 \mathrm{~min}$. 


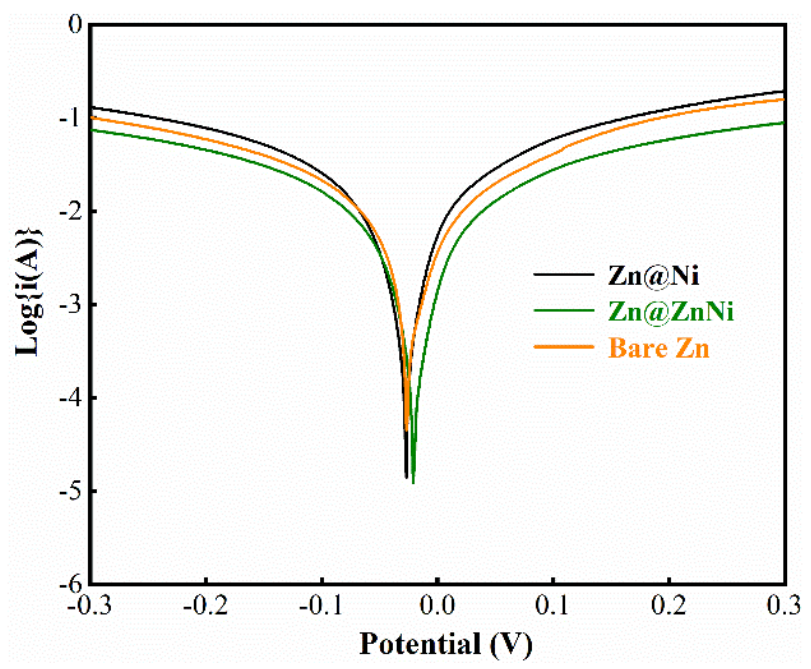

Figure S3. Linear polarization curves of Zn@ZnNi, Zn@Ni and bare $\mathrm{Zn}$ anode in the symmetric cell.

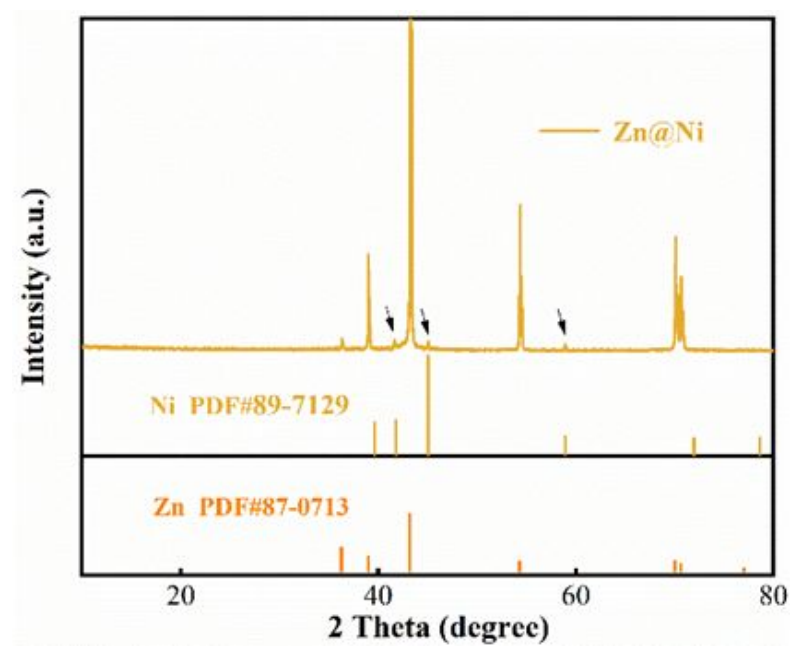

Figure S4. The XRD pattern of the Zn@Ni.

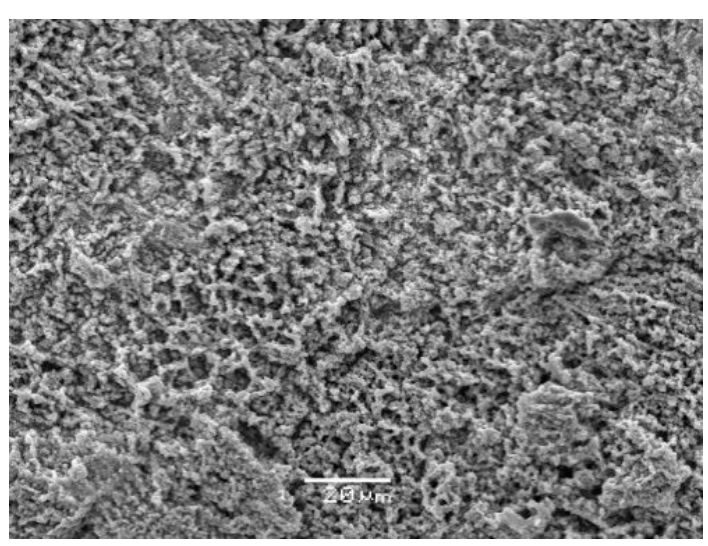

Figure S5. The SEM images of the Zn@Ni. 


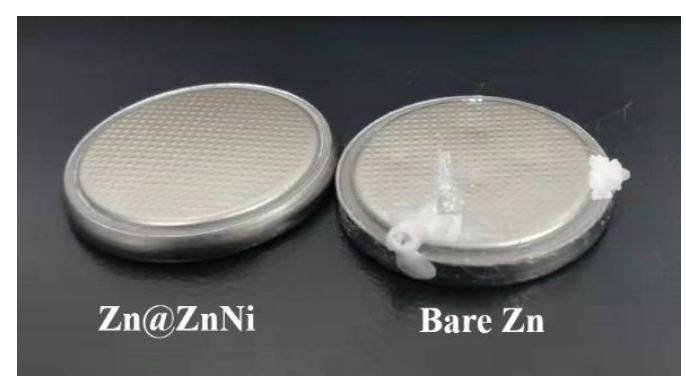

Figure S6. The photos of the symmetry cell with bare Zn and Zn@ZnNi anode.
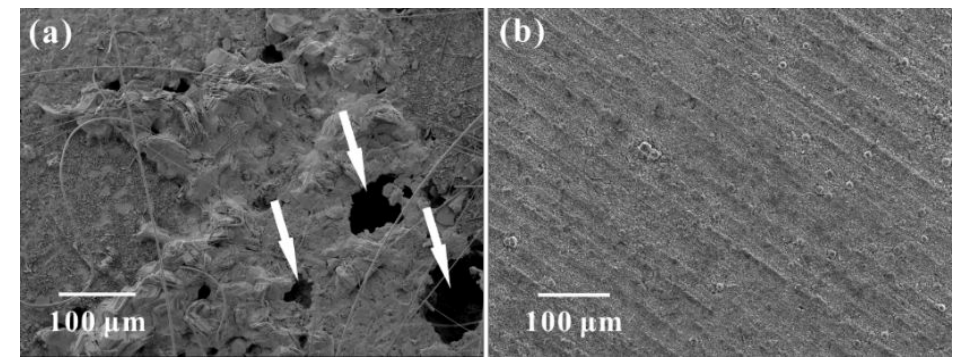

Figure S7. The SEM images of the (a) bare Zn and (b) Zn@ZnNi anode in the full cell after 100 cycles at $0.5 \mathrm{~A} \mathrm{~g}^{-1}$.

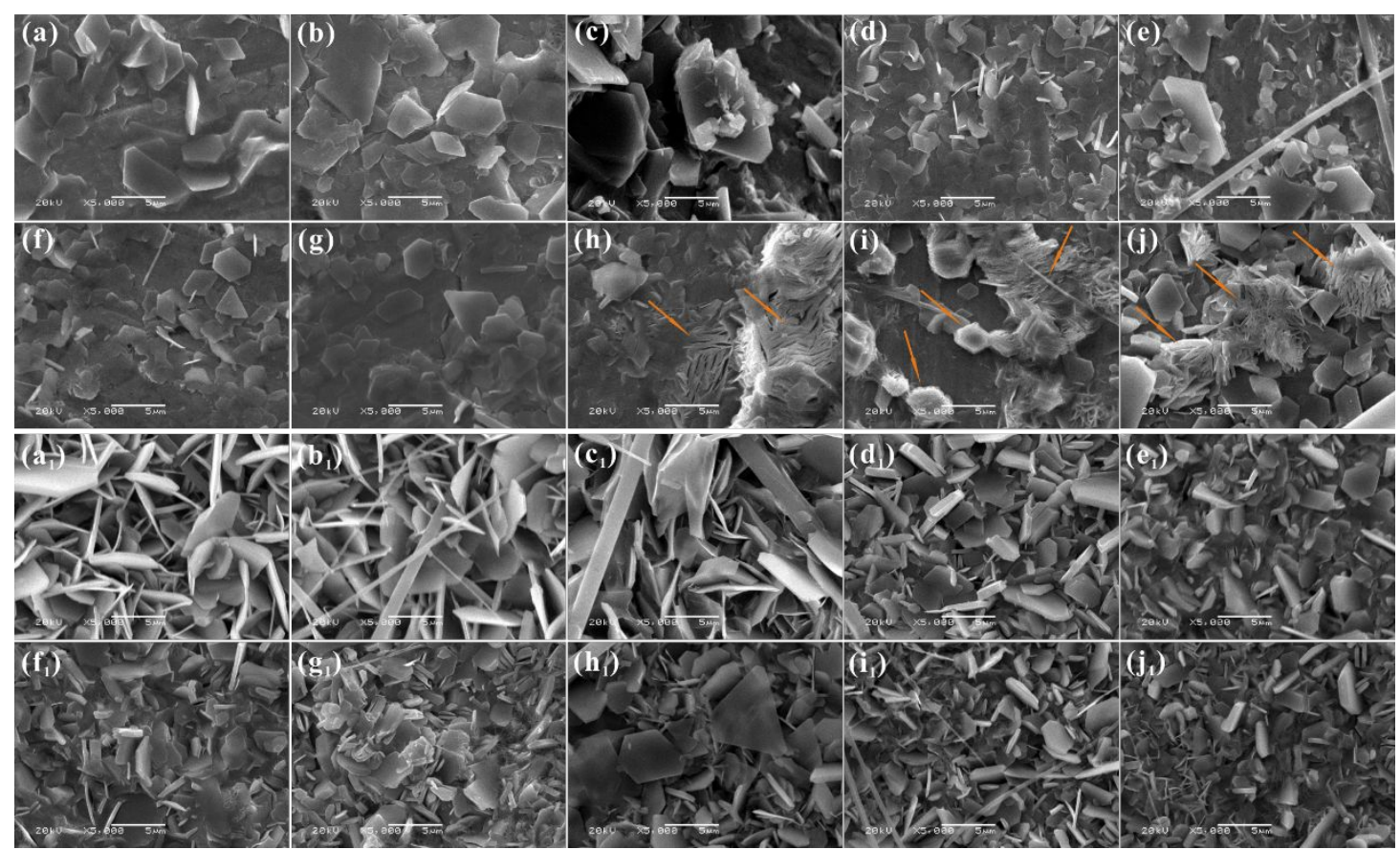

Figure S8. The SEM images of Zn nuclei deposited on the bare Zn (a-j) and Zn@ZnNi $\left(a_{1}-j_{1}\right)$ at the various current densities, where the images of $a-j$ and the $a_{1}-j_{1}$ are the corresponding enlargement of Figure 2 in the manuscript. 

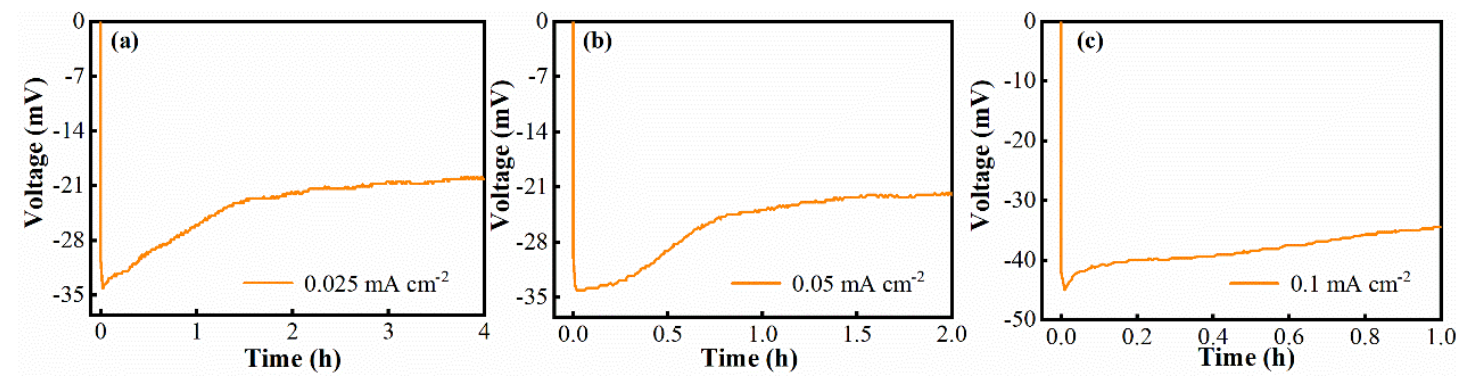

Figure S9. The voltage profiles of the $\mathrm{Zn}$ deposition on the bare $\mathrm{Zn}$ at a current density of (a) 0.025 $\mathrm{mA} \mathrm{cm}{ }^{-2}$, (b) $0.05 \mathrm{~mA} \mathrm{~cm}^{-2}$ and (c) $0.1 \mathrm{~mA} \mathrm{~cm}^{-2}$. The areal capacity is $0.1 \mathrm{mAh} \mathrm{cm}^{-2}$.
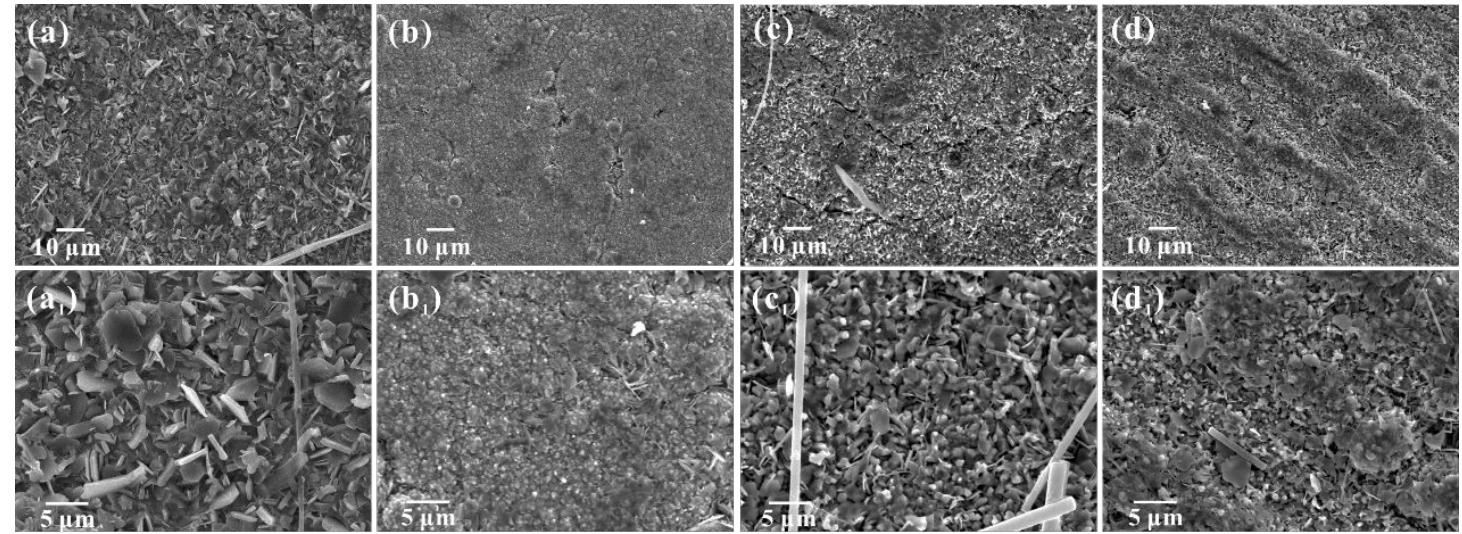

Figure S10. The SEM images of Zn nuclei deposited on Zn@ZnNi for (a) 3 min, (b) 30 min, (c) 60 min, and (d) $90 \mathrm{~min}$ at a current density of $2 \mathrm{~mA} \mathrm{~cm}{ }^{-2}$, where the images of $\left(\mathrm{a}_{1}\right),\left(\mathrm{b}_{1}\right),\left(\mathrm{c}_{1}\right)$, and $\left(\mathrm{d}_{1}\right)$ are the enlargement of the (a), (b), (c), and (d), respectively. 

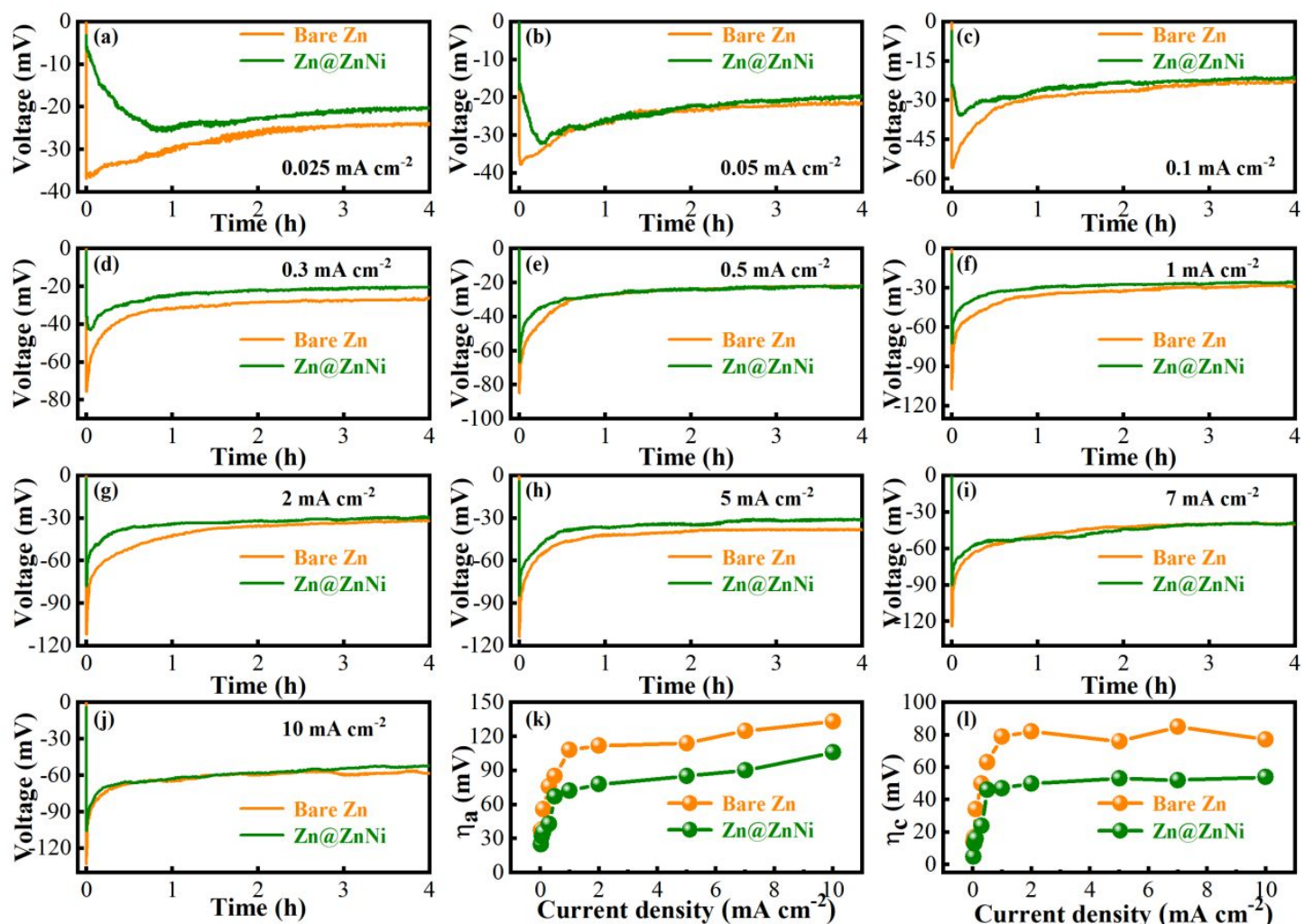

Figure S11. The voltage profiles of the $\mathrm{Zn}$ deposition on the bare $\mathrm{Zn}$ and $\mathrm{Zn} @ \mathrm{ZnNi}$ at a current density of (a) $0.025 \mathrm{~mA} \mathrm{~cm}^{-2}$, (b) $0.05 \mathrm{~mA} \mathrm{~cm}^{-2}$, (c) $0.1 \mathrm{~mA} \mathrm{~cm}^{-2}$, (d) $0.3 \mathrm{~mA} \mathrm{~cm}^{-2}$, (e) $0.5 \mathrm{~mA} \mathrm{~cm}$ ${ }^{2}$, (f) $1 \mathrm{~mA} \mathrm{~cm}^{-2}$, (g) $2 \mathrm{~mA} \mathrm{~cm}^{-2}$, (h) $5 \mathrm{~mA} \mathrm{~cm}^{-2}$, (i) $7 \mathrm{~mA} \mathrm{~cm}^{-2}$, (j) $10 \mathrm{~mA} \mathrm{~cm}^{-2}$. (k) The relationship between the overpotential spike $\left(\eta_{\mathrm{a}}\right)$ and current density, (l) the relationship between the nucleation overpotential and current density.
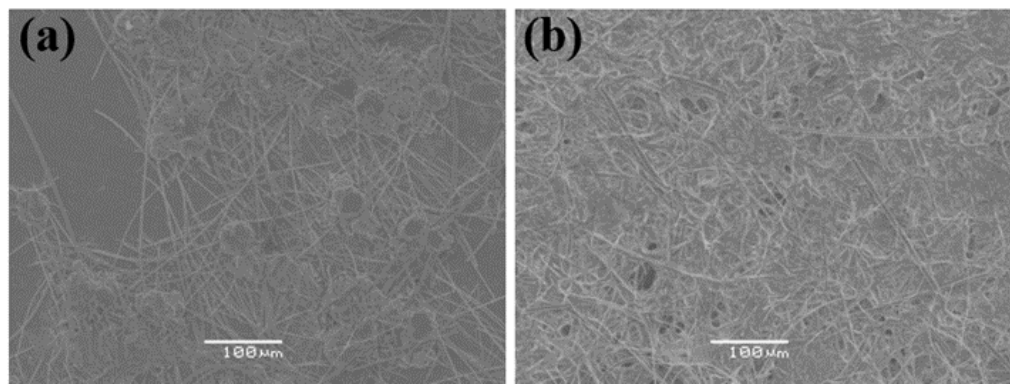

Figure S12. The SEM images of the Zn deposition on the bare $\mathrm{Zn}$ at $2 \mathrm{~mA} \mathrm{~cm}^{-2}$ for (a) $1 \mathrm{~h}$ and (b) $4 h$. 

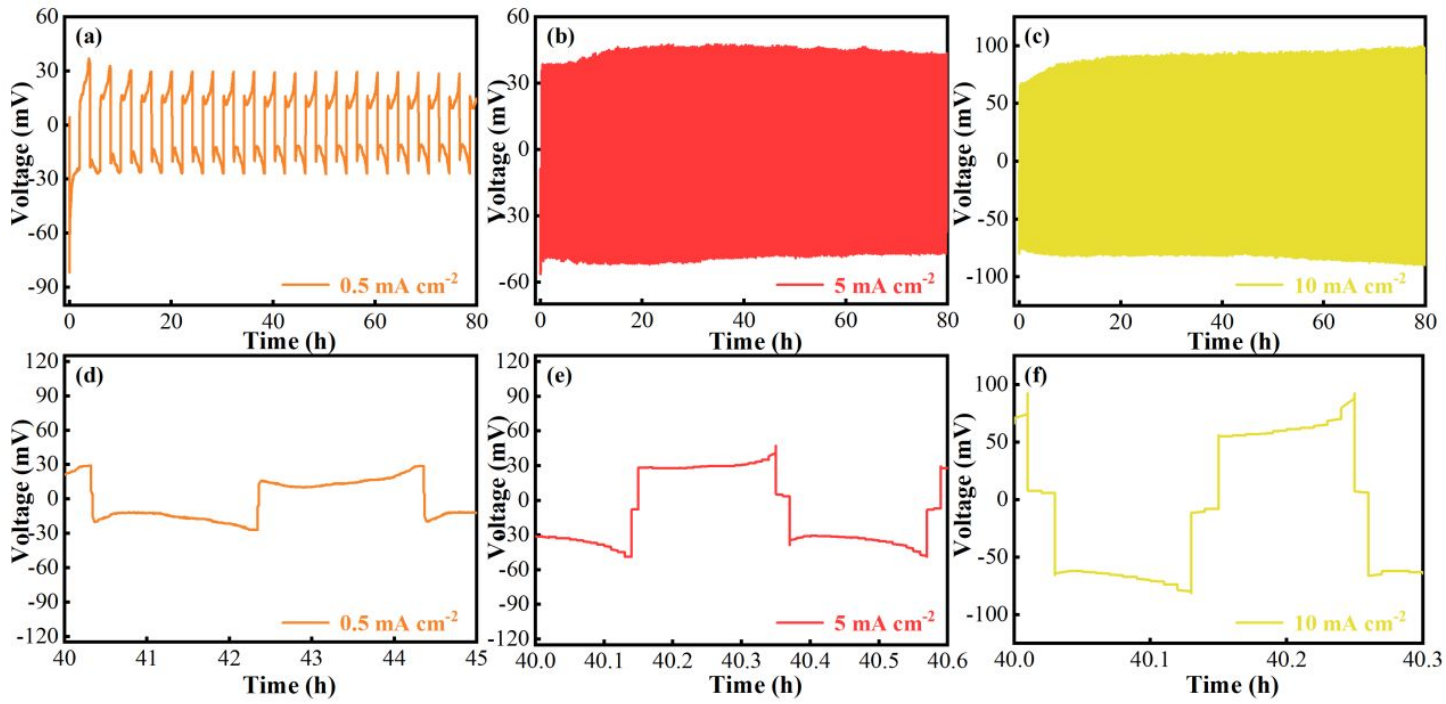

Figure S13. The cycling performance of the bare $\mathrm{Zn}$ anode in the symmetric cell at (a, d) $0.5 \mathrm{~mA}$ $\mathrm{cm}^{-2}$, (b, e) $5 \mathrm{~mA} \mathrm{~cm}^{-2}$ and (c, f) $10 \mathrm{~mA} \mathrm{~cm}^{-2}$. The areal capacity is fixed as $1 \mathrm{mAh} \mathrm{cm}$.

(a)

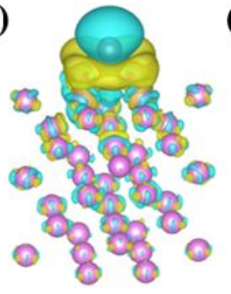

(b)

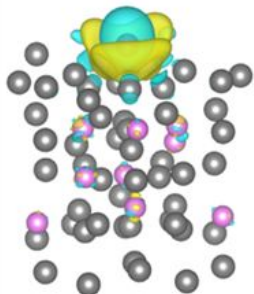

(c)

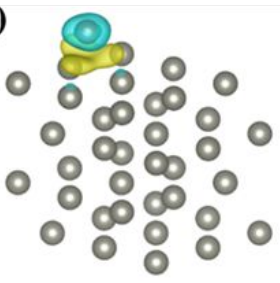

Figure S14. Charge density diagram and charge density differences of the (a)Ni, (b) $\mathrm{ZnNi}$, and (c) $\mathrm{Zn}$ with $\mathrm{Zn}^{2+}$ adsorption.

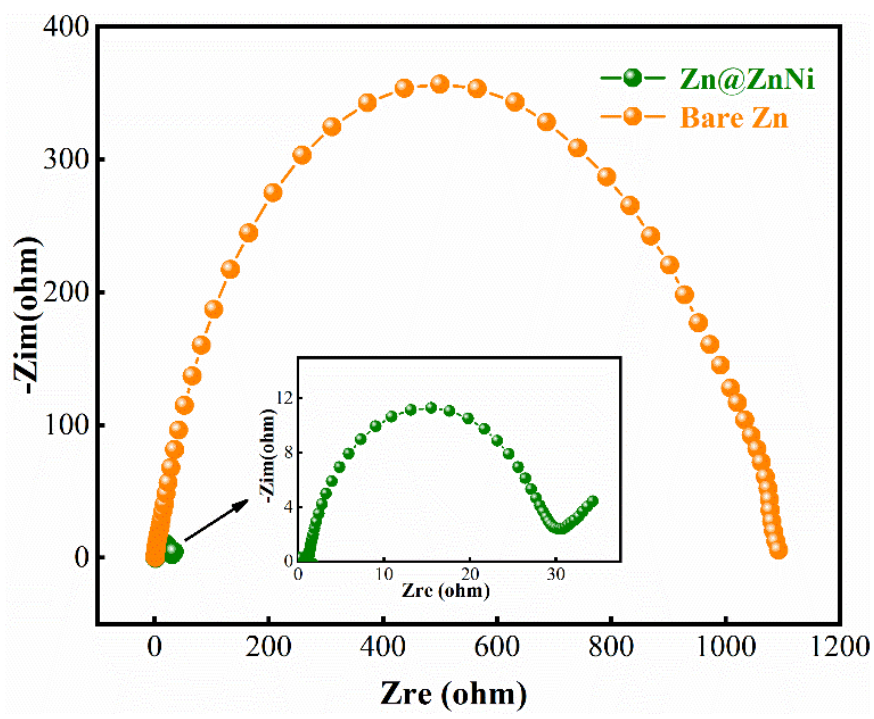

Figure S15. The EIS curves of the Zn@ZnNi and bare Zn anode in the symmetric cell. 


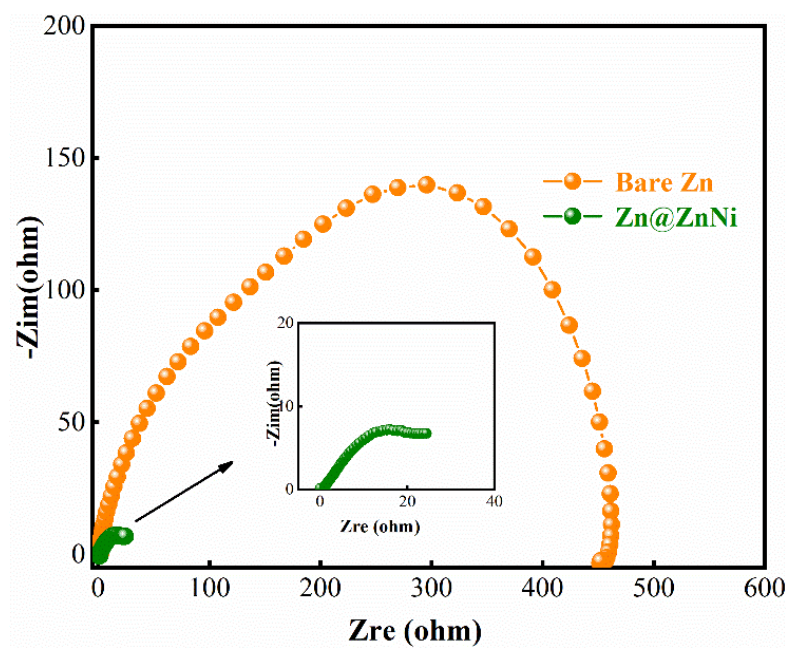

Figure S16. The EIS curves (original data) of the $\mathrm{Zn} @ \mathrm{ZnNi}$ and bare $\mathrm{Zn}$ anode in the symmetric cell after 100 cycles at $2 \mathrm{~mA} \mathrm{~cm}^{-2}$.

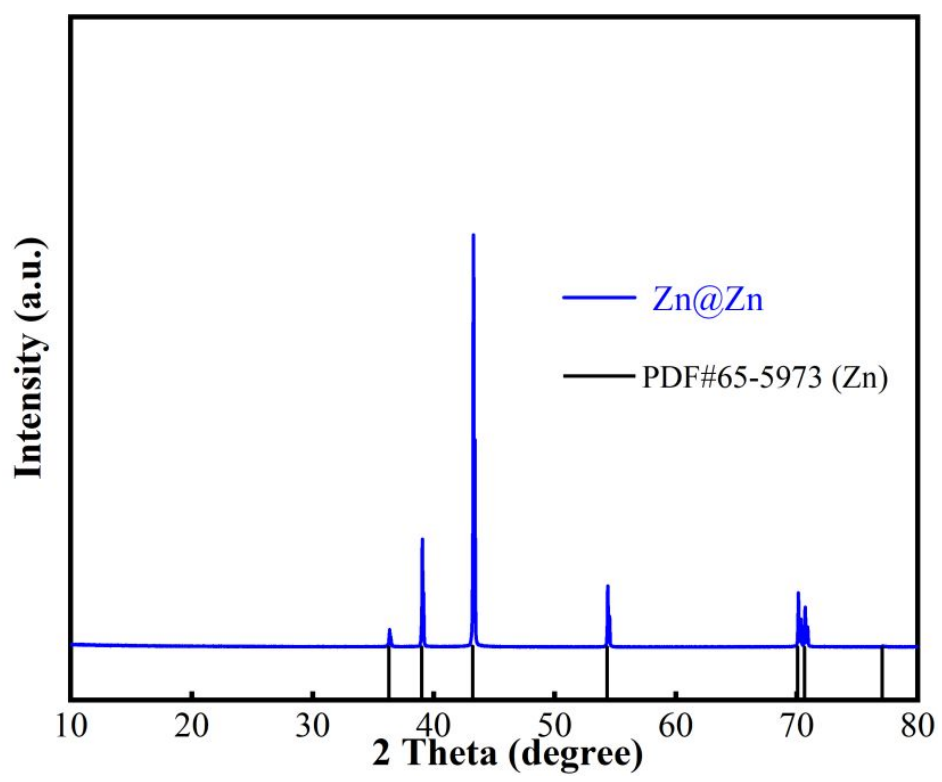

Figure S17. The XRD pattern of the bare Zn coating on the Zn foil (Zn@Zn).

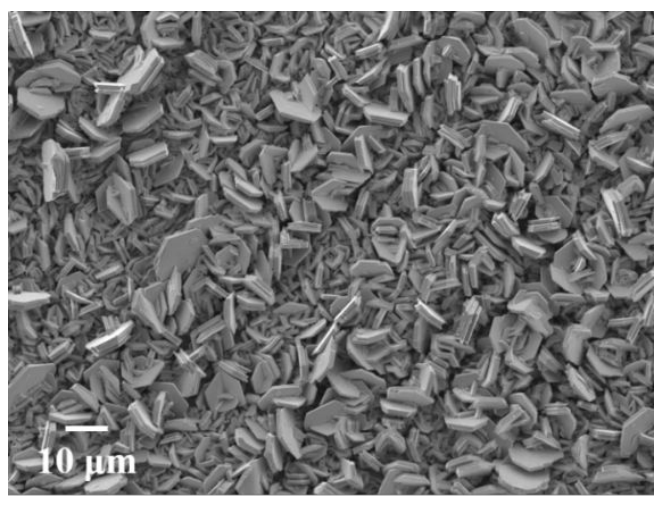

Figure S18. The SEM image of the bare Zn coating on the Zn foil (Zn@Zn). 

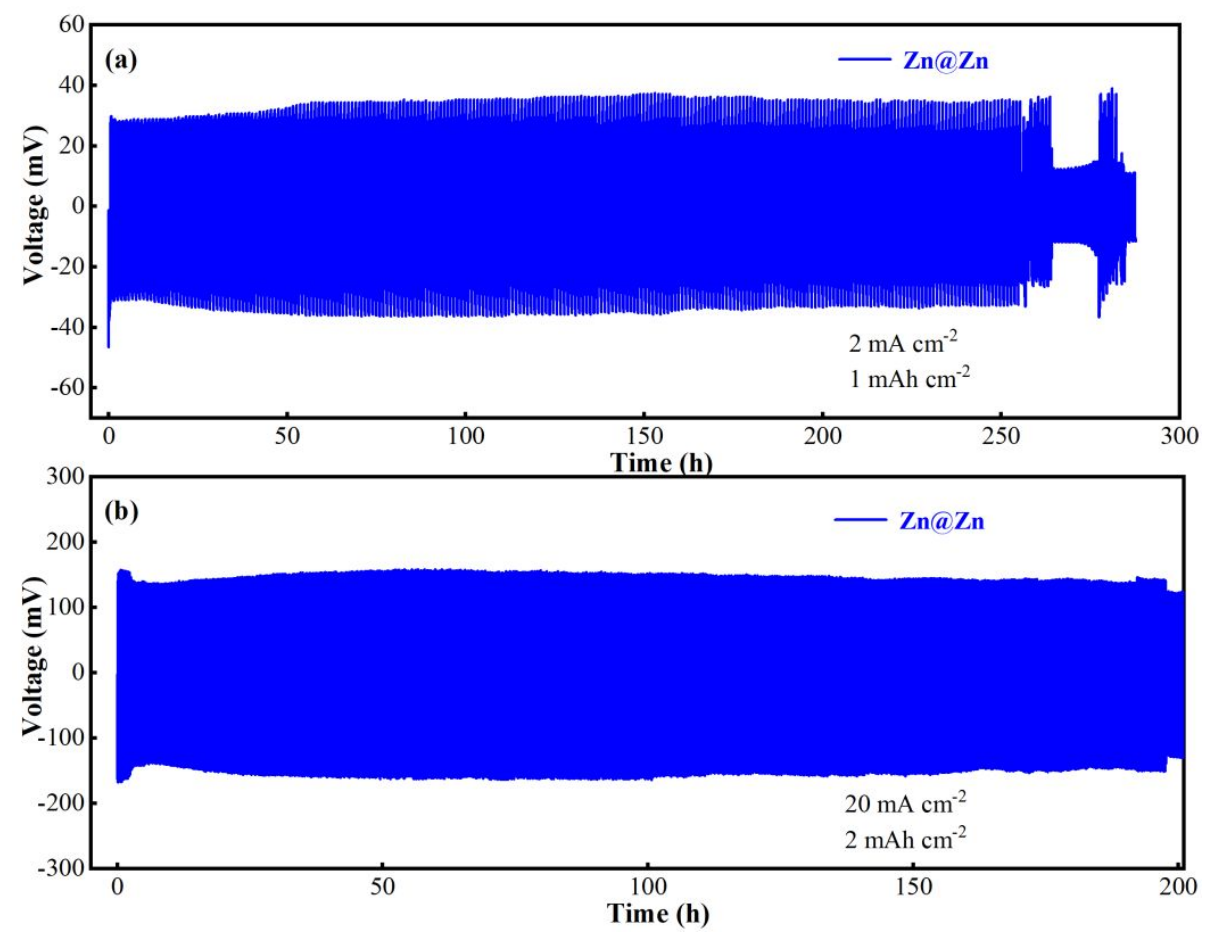

Figure S19. The cycling performance of the Zn@Zn anode (bare $\mathrm{Zn}$ coating on the $\mathrm{Zn}$ ) in the symmetric cell at (a) $2 \mathrm{~mA} \mathrm{~cm}^{-2}$ and (b) $20 \mathrm{~mA} \mathrm{~cm}^{-2}$.

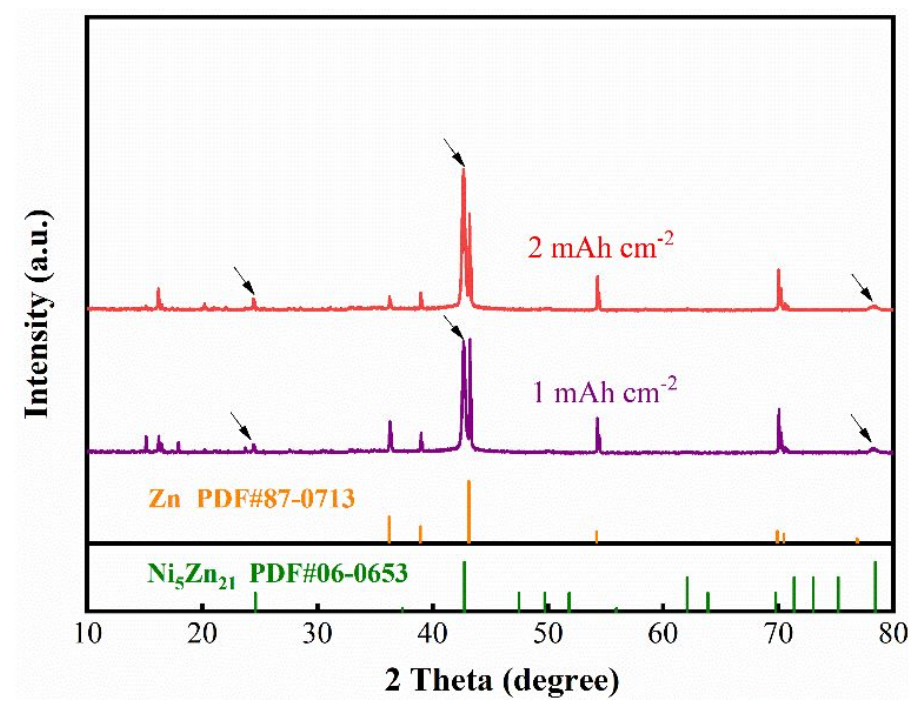

Figure S20. XRD patterns of $\mathrm{Zn} @ \mathrm{ZnNi}$ anode after stripping at $2 \mathrm{~mA} \mathrm{~cm}{ }^{-2}$ for $1 \mathrm{mAh} \mathrm{cm}^{-2}$ and $2 \mathrm{mAh} \mathrm{cm}^{-2}$. 

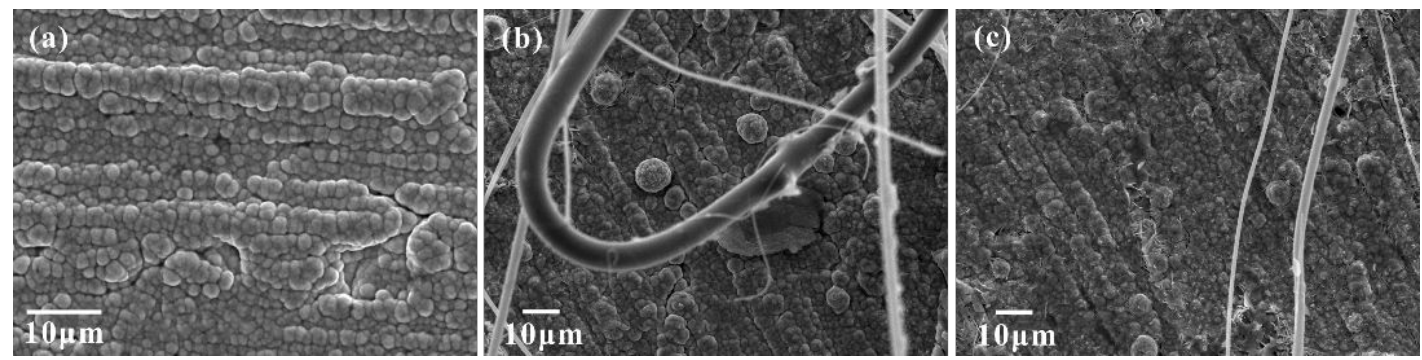

Figure S21. The SEM images of (a) original Zn@ZnNi, after stripping at $2 \mathrm{~mA} \mathrm{~cm}-2$ for (b) $1 \mathrm{mAh}$ $\mathrm{cm}^{-2}$ and (c) $2 \mathrm{mAh} \mathrm{cm}{ }^{-2}$.
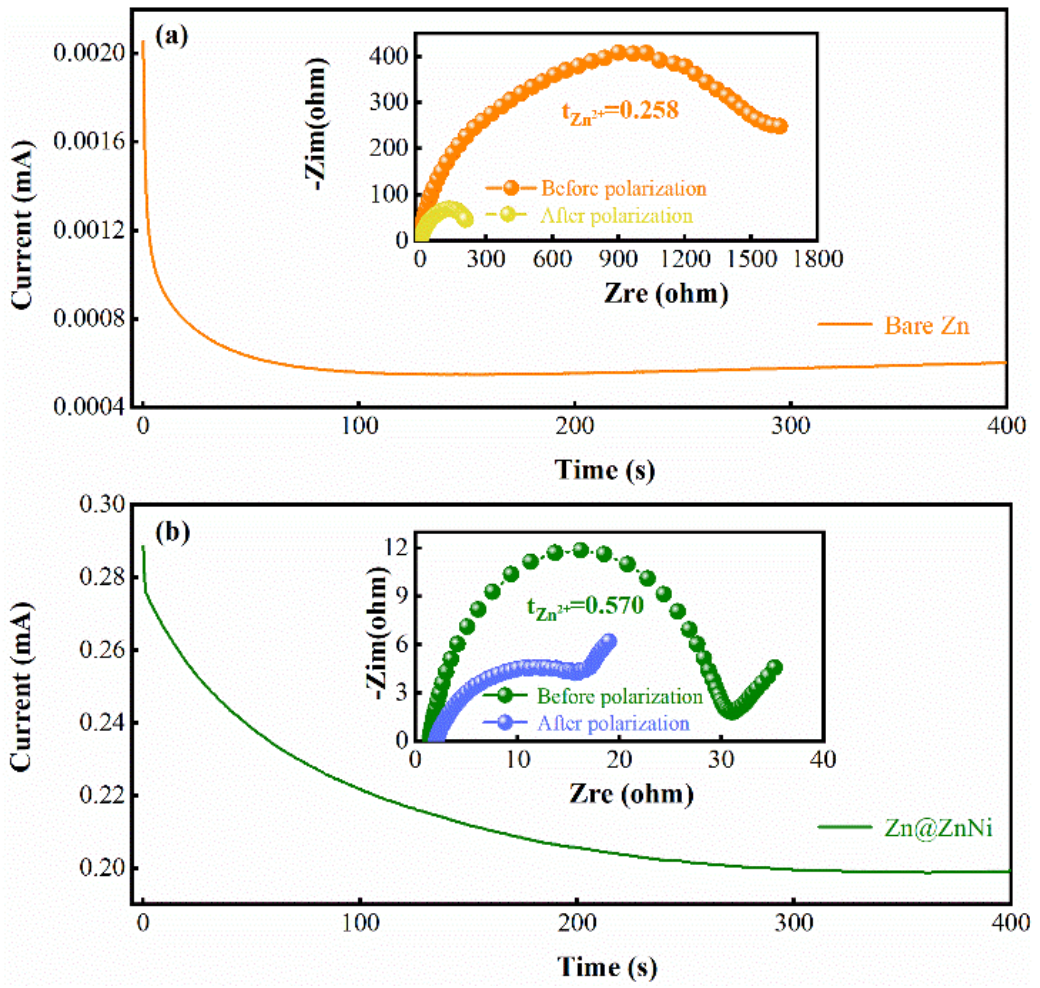

Figure S22. Current-time plots of bare Zn and Zn@ZnNi in the symmetric cells after the application of a constant potential $(25 \mathrm{mV})$. The insets display the impedance spectra before and after polarization.

The $\mathrm{Zn}$ ion transference number $\left(\mathrm{t}^{+}\right)$as a reference for the bare $\mathrm{Zn}$ and $\mathrm{Zn} @ \mathrm{ZnNi}$ was calculated by using Equation $1:^{1-2}$

$$
t^{+}=\frac{I_{s}\left(\Delta V-I_{0} R_{0}\right)}{I_{0}\left(\Delta V-I_{S} R_{S}\right)}
$$

where $\Delta \mathrm{V}$ is the potential $(25 \mathrm{mV})$ applied in the symmetric cell; $\mathrm{I}_{0}$ and $\mathrm{I}_{\mathrm{S}}$ refer to the initial and steady-state current, respectively; $\mathrm{R}_{0}$ and $\mathrm{R}_{\mathrm{S}}$ refer to the initial and steadystate resistances, respectively. 


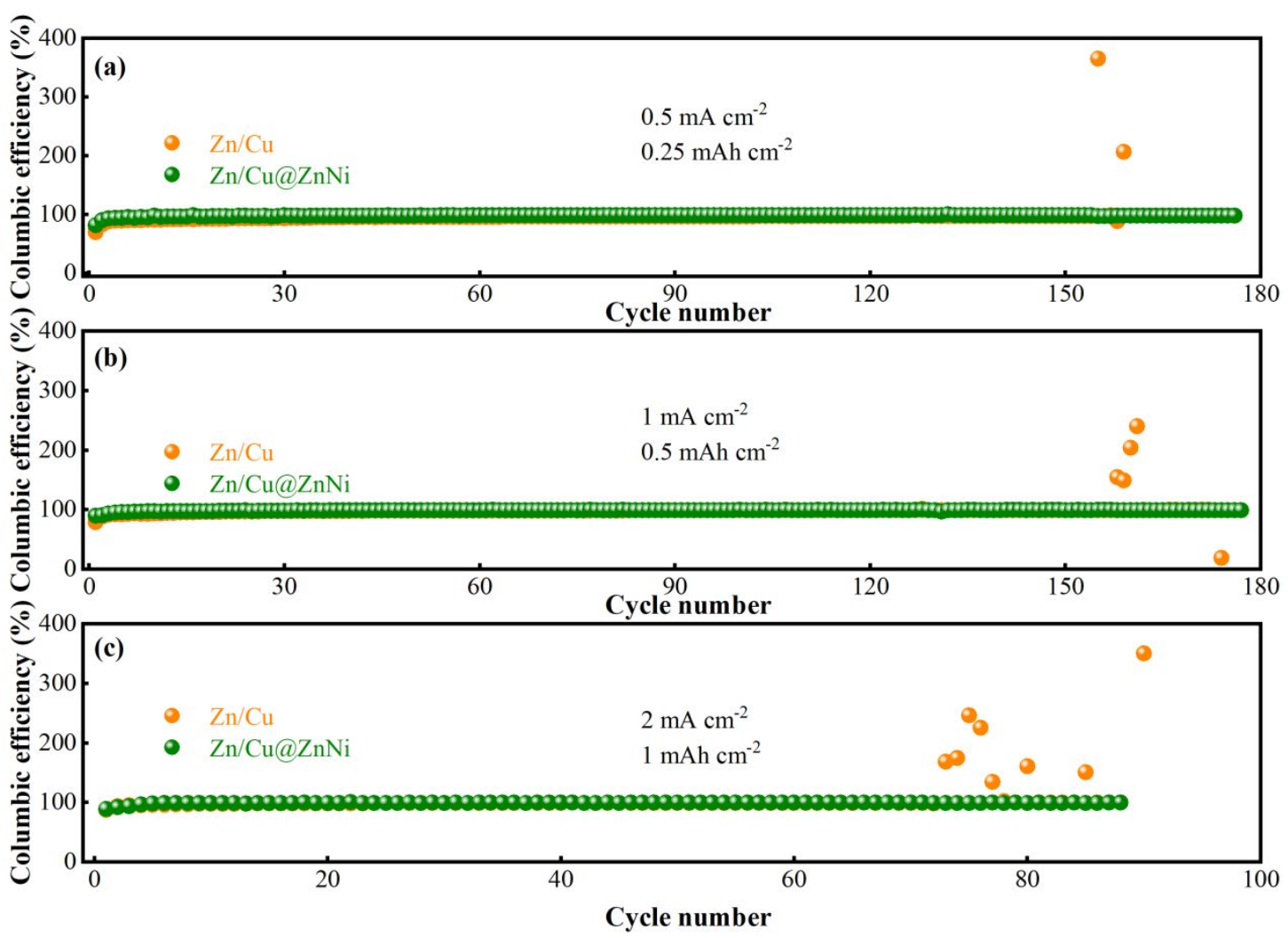

Figure S23. The Coulombic efficiency of the $\mathrm{Zn} / \mathrm{Cu}$ and $\mathrm{Zn@ZnNi} \mathrm{cell} \mathrm{at} \mathrm{the} \mathrm{current} \mathrm{density} \mathrm{of} \mathrm{(a)}$ $0.5 \mathrm{~mA} \mathrm{~cm}^{-2}$, (b) $1 \mathrm{~mA} \mathrm{~cm}^{-2}$, and (c) $2 \mathrm{~mA} \mathrm{~cm}^{-2}$.

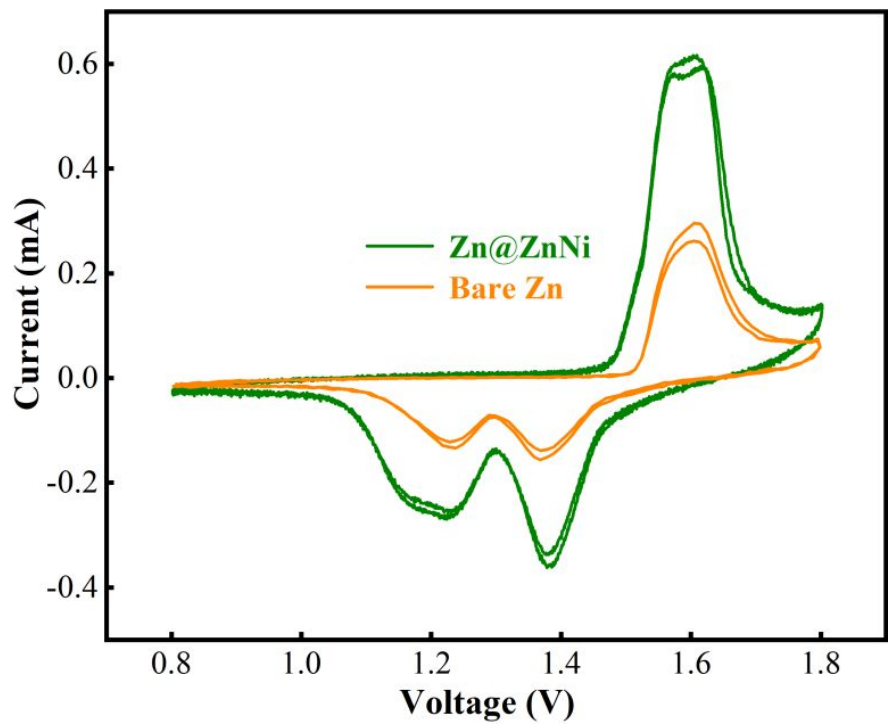

Figure S24. The cyclic voltammetry (CV) measurement at a scan rate of $0.1 \mathrm{mV} \mathrm{s}^{-1}$. 


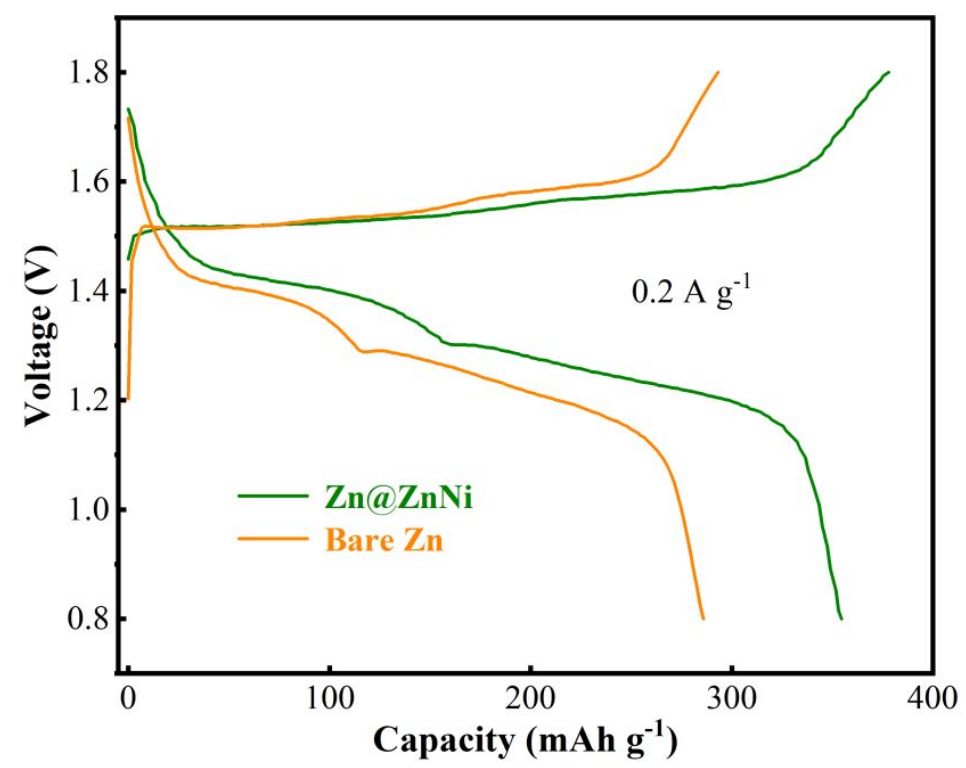

Figure S25. The discharge-charge curves of the bare Zn and $\mathrm{Zn@ZnNi} \mathrm{anode} \mathrm{in} \mathrm{the} \mathrm{full} \mathrm{cell} \mathrm{after}$ the second cycle at $0.2 \mathrm{~A} \mathrm{~g}^{-1}$.

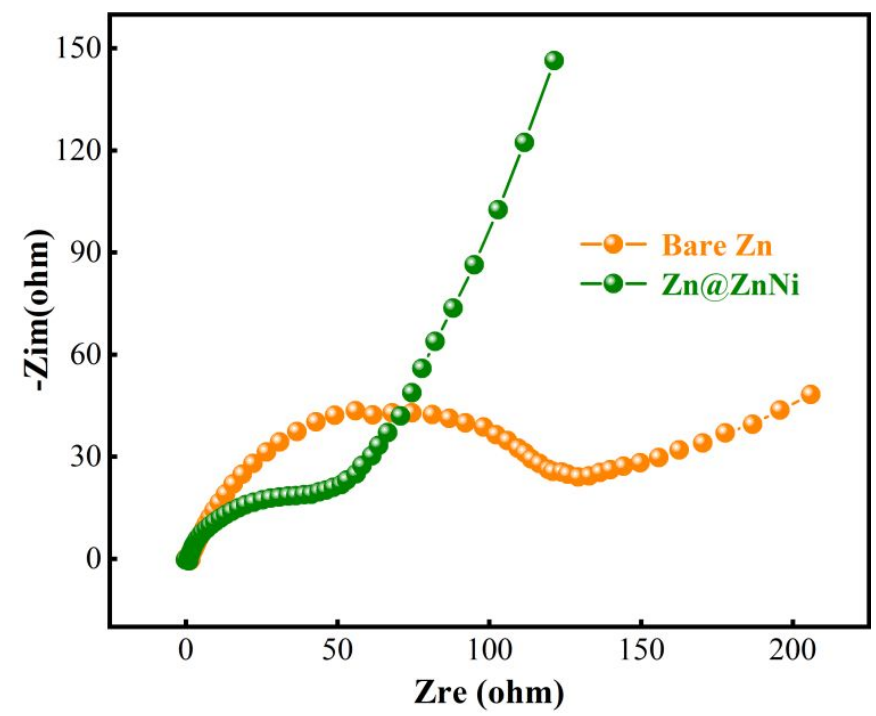

Figure S26. The EIS curves (original data) of the Zn@ZnNi and bare $\mathrm{Zn}$ anode in the full cell after 100 cycles at $0.5 \mathrm{~A} \mathrm{~g}^{-1}$. 


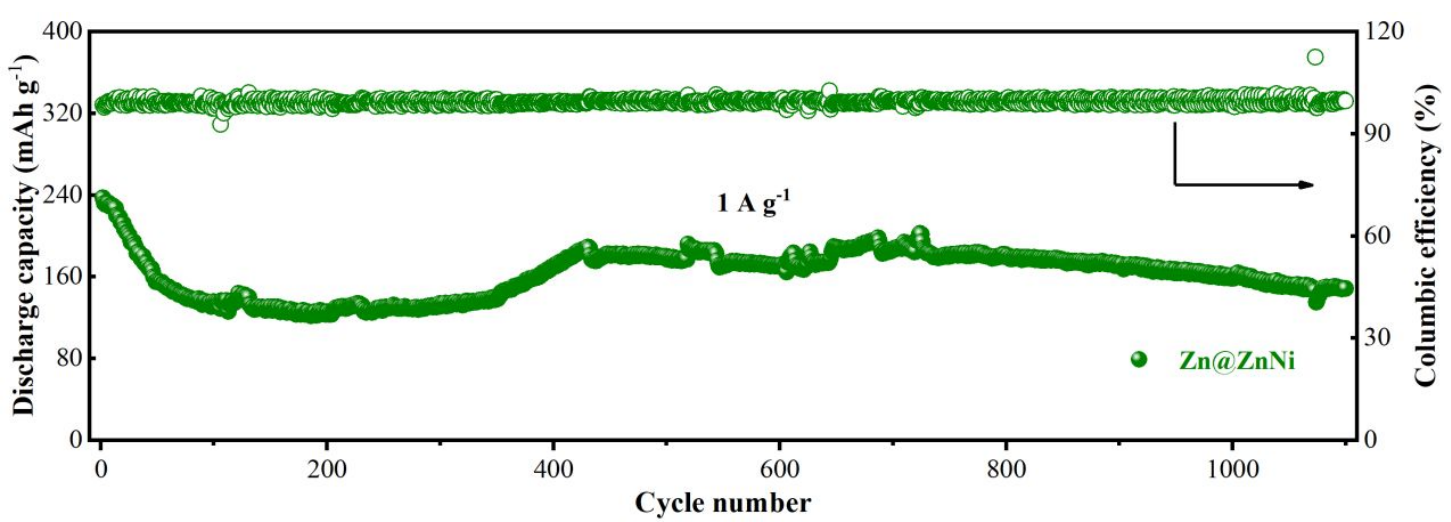

Figure S27. The cycling performance of the full cell with $\mathrm{Zn@ZnNi} \mathrm{anode} \mathrm{at} 1 \mathrm{~A} \mathrm{~g}^{-1}$.

\section{Reference}

1. Hao, J.; Li, B.; Li, X.; Zeng, X.; Zhang, S.; Yang, F.; Liu, S.; Li, D.; Wu, C.; Guo, Z., An In-Depth Study of Zn Metal Surface Chemistry for Advanced Aqueous Zn-Ion Batteries. Advanced Materials 2020, 32 (34), 2003021.

2. Zhao, Z.; Zhao, J.; Hu, Z.; Li, J.; Li, J.; Zhang, Y.; Wang, C.; Cui, G., Long-life and deeply rechargeable aqueous $\mathrm{Zn}$ anodes enabled by a multifunctional brightenerinspired interphase. Energy \& Environmental Science 2019, 12 (6), 1938-1949. 